\title{
Identity Styles and Conflict Resolution Styles: Associations in Mother-Adolescent Dyads
}

\author{
Lies Christine Missotten • Koen Luyckx • \\ Susan Branje · Janne Vanhalst $\cdot$ Luc Goossens
}

Received: 16 July 2010/Accepted: 3 November 2010/Published online: 23 November 2010

(C) Springer Science+Business Media, LLC 2010

\begin{abstract}
Adolescent identity and parent-adolescent conflict have each attracted considerable research interest. However, few studies have examined the important link between the two constructs. The present study examined the associations between adolescent identity processing styles and adolescent conflict resolution styles in the mother-adolescent dyad. Questionnaires about conflict frequency and resolution were completed by 796 adolescents (66\% female, mostly Caucasian) and their mothers. Adolescents also completed a measure on identity styles. Each identity style was hypothesized to relate to a specific conflict resolution behavior. Hierarchical regression analyses showed that the information-oriented identity style was positively associated with positive problem solving and negatively with conflict engagement and withdrawal, the normative style was positively associated with compliance, and, finally, the diffuse-avoidant style was positively associated with withdrawal and conflict engagement and negatively with positive problem solving. Our results demonstrated that the way in which adolescents tackle identity-relevant issues is related to the way in which they deal with conflicts with their mothers. Implications and suggestions for future research are discussed.
\end{abstract}

Keywords Mid-adolescence $\cdot$ Identity styles $\cdot$ Conflict frequency · Conflict resolution · Mother-adolescent dyad

L. C. Missotten $(\bowtie) \cdot$ K. Luyckx $\cdot$ J. Vanhalst $\cdot$ L. Goossens Department of Psychology, School Psychology and Child and Adolescent Development (SCAD), Catholic University of Leuven, Tiensestraat 102, 3000 Leuven, Belgium e-mail: lies.missotten@psy.kuleuven.be

\section{S. Branje}

Research Centre Adolescent Development, Utrecht University, P.O. Box 80140, 3508 TC Utrecht, The Netherlands

\section{Introduction}

Adolescence is widely recognized as the core developmental period for the foundation and formation of a healthy identity (Erikson 1968). Adolescents have to make important choices that impact on several areas of their current and future lives. For instance, they have to choose an education that fits their interests and capacities, and they have to engage in long-term friendships and intimate relationships. In line with Erikson's view on identity development, several authors have stressed that the formation of such a well-integrated identity should be conceptualized as a dynamic process of person-context interactions (Adams and Marshall 1996; Kroger 2003; Lichtwarck-Aschoff et al. 2008). This process takes place in the various contexts or microsystems in adolescents' lives (i.e., family, peer group, and school).

The family is the primary context in which adolescents construct an identity of their own (Bronfenbrenner 1989). Relationships with parents have to be renegotiated in order for adolescents to gain more autonomy about important life choices (Grotevant and Cooper 1985). This redefining of the relationship involves a shift from unilateral parental authority towards a more horizontal and symmetrical relationship (Smetana 1989; Youniss and Smollar 1985). Parents and adolescents often differ in their expectations about the timing of this redefinition (Collins et al. 1997; Smetana 1989; Smetana et al. 2003). Several theorists, therefore, have argued that a certain amount of conflict between adolescents and parents is inevitable (Adams and Laursen 2007; Collins and Laursen 1992; Deković et al. 1997) and even necessary for this relationship shift to emerge (Goossens 2006; Kunnen 2006; Steinberg 1990). In essence, acquiring an identity often develops in tandem with parent-adolescent conflicts, with both constructs 
potentially influencing one another. Establishing an independent identity can give rise to parent-adolescent conflicts and different ways of dealing with these conflicts, whereas, at the same time, a successful resolution of such conflicts can play favorably into identity development (Bosma and Kunnen 2001).

The purpose of the present study was to investigate, for the first time, how identity formation was related to the way adolescents handle conflicts with their parents. Specifically, we wanted to examine whether adolescents' identity processing styles are differentially related to conflict resolution styles. Despite the hypothesized inherent relationship between both sets of variables (Bosma and Kunnen 2001), the relationship between identity styles and conflict resolution behavior has never been addressed empirically.

\section{Identity Styles}

Inspired by Erikson (1968), the processes of identity exploration and commitment are considered essential components for developing a mature identity. Marcia (1966) was among the first to conceptualize these dimensions into a fourfold scheme of identity statuses. Exploration refers to the process of self-examination and discovery of one's goals, beliefs, and values in several domains, whereas commitment refers to the consolidation of this process and the subsequent making of identity choices.

As an extension of identity status theory, Berzonsky (1989, 1990) focused in depth on the exploration dimension and approached identity formation mainly from a social-cognitive angle. Specifically, he focused on how adolescents process identity-relevant information in order to cope with salient problems concerning their education, relationships, and values. In doing so, Berzonsky (1990) defined three identity styles: the information-oriented, normative, and diffuse-avoidant identity style. First, information-oriented individuals actively seek out, examine, and evaluate relevant information when dealing with identity issues. They have an open-minded view (Berzonsky and Sullivan 1992) and, consequently, are prepared to accommodate their goals and values to new information. This identity style was positively associated with problem-focused coping strategies, high self-esteem, and a constructive and empathic interpersonal attitude (Berzonsky 1992; Nurmi et al. 1997; Smits et al., in press). Second, normative individuals rely strongly on the expectations held by significant others, like parental figures. They tend to follow social conventions and are closed to dissonant information that threatens their conservative self-views. Although they report high self-esteem and are at low risk for problem behavior (Adams et al. 2001; Nurmi et al. 1997), these individuals rely strongly on avoidance tactics when dealing with stressors (Berzonsky 1992). Third, diffuse-avoidant adolescents tend to delay and procrastinate important personal decisions. They are present-oriented (Luyckx et al. 2010) and rely on situational demands that force them to make a certain decision. This style is associated with emotion-focused coping strategies such as distancing, wishful thinking, and tension reduction (Berzonsky 1992). Diffuse-avoidant individuals experience social and behavioral problems and have immature interpersonal relationships (Adams et al. 2001; Nurmi et al. 1997). Hence, each of the three identity styles has a specific set of socialcognitive and psychosocial correlates.

Only a handful of studies, however, has focused on the link between identity styles and family variables (e.g., Berzonsky 2004; Berzonsky et al. 2007; Smits et al. 2008). These studies have shown that the information-oriented style was related to authoritative parenting and parental solicitation of information; the normative style to both authoritative and authoritarian parenting and positive parent-adolescent relationships; and the diffuse-avoidant style primarily to permissive parenting and overall negative parent-adolescent relationships (Berzonsky 2004; Berzonsky et al. 2007). However, no studies have been conducted addressing the link between identity styles and conflict resolution styles in the family.

\section{Conflict Resolution in the Adolescent-Parent Relationship}

Conflict is a common feature of all human relationships. A meta-analysis by Laursen et al. (1998) revealed that conflicts with parents occur most frequently throughout early adolescence and decrease gradually thereafter. However, the intensity of conflicts with parents was found to increase from early to middle adolescence, as confirmed in longitudinal studies (De Goede et al. 2009; McGue et al. 2005). In addition to frequency and intensity, several authors have identified conflict management or resolution skills as an important aspect of conflict (Collins and Laursen 1992; Shantz 1987). Acquiring these skills is crucial during adolescence because relationships become gradually more important (Adams and Laursen 2001). Moreover, conflicts are not necessarily detrimental for adolescent development. The relational context in which the conflicts take place and the way conflicts are handled may be more important than the conflicts themselves (Adams and Laursen 2007; Branje et al. 2009).

In line with the literature on conflict resolution in married couples (Kurdek 1994), four conflict resolution styles 
are distinguished in research on adolescent conflicts: positive problem solving, conflict engagement, withdrawal, and compliance (Laursen and Collins 1994; Laursen et al. 2001; Rubenstein and Feldman 1993; Van Doorn et al. 2008). Positive problem solving involves trying to understand the other's point of view and negotiating the conflict effectively in order to find a compromise. Conflict engagement involves destructive behaviors like attacking the other verbally, being defensive, or losing self-control. Withdrawal involves avoiding the problem, avoiding talking, and becoming distant. Compliance involves giving into the other party without expressing one's point of view. Among these four styles, withdrawal and compliance were found to be the most common conflict resolution behaviors among adolescents in relation to their parents (Laursen 1993; Montemayor and Hanson 1985).

Findings on developmental trends in adolescents' use of the various conflict resolution styles have been mixed. Tucker et al. (2003) found that older adolescents reported less constructive conflict resolution with parents. These authors suggested that the shift in power balance between parents and their adolescents towards a more egalitarian relationship could hamper effective conflict resolution. However, in a recent longitudinal study (Van Doorn et al. 2008), positive problem solving increased from early to middle adolescence, and conflict engagement and withdrawal declined around mid-adolescence. Some studies, therefore, found evidence in support of a deterioration of adolescent conflict resolution with advancing age, whereas other studies found conflict resolution behaviors to mature over time.

Clear findings, by contrast, have emerged regarding the link between conflict resolution styles and adolescent psychological well-being. Constructive problem solving was associated with several positive outcomes such as high levels of school effort and grades, high self-esteem, and low levels of depression and risky behavior (Rubenstein and Feldman 1993; Tucker et al. 2003), whereas hostile conflict resolution in the adolescentmother relationship was positively associated with delinquency (Van Doorn et al. 2008). Hence, effective conflict resolution was generally linked to better adjustment. Because adolescents typically have closer relationships with their mother than their father, or because mothers are more deeply involved in adolescents' daily life, conflict resolution styles in the mother-adolescent relationship are often thought to have stronger implications for adolescent adjustment (Tucker et al. 2003). Accordingly, adolescents consistently reported more conflicts with mothers than with fathers or siblings (Laursen and Collins 1994). As a consequence, the emphasis in research on adolescent conflict resolution styles has been on mother-adolescent relationships.

\section{The Present Study}

The present study addressed two main research questions. The first question concerned the links between identity styles and conflict frequency in the mother-adolescent dyad. We expected a negative association between the information-oriented and normative identity styles on the one hand and conflict frequency on the other. The underlying mechanisms explaining both negative associations might be different. Because information-oriented adolescents have an open and empathic attitude, we expected to find a low conflict rate between information-oriented adolescents and their mothers. Because the normative style is associated with an obedient and conformist attitude towards parents, we expected normative individuals to report low levels of conflict. With respect to the diffuseavoidant identity style, we expected a positive link with conflict frequency because adolescents using this style are present-oriented and tend to procrastinate important life decisions.

The second question addressed how identity styles and conflict resolution styles in the mother-adolescent dyad were interrelated. We hypothesized that the way in which adolescents tackled identity-relevant issues might be related to how they dealt with conflicts in the family. Based on the extant identity literature, each identity style was hypothesized to relate to a specific pattern of conflict resolution behaviors. First, we expected the informationoriented identity style to be positively related to positive problem solving because this style is associated with perspective taking and problem-focused coping. Second, because normative individuals strongly conform to the goals and values of significant others (e.g., their parents), the normative identity style is expected to be accompanied primarily by compliance. A positive association with withdrawal might also be plausible because these adolescents have a strong tendency to protect their identity structure. Hence, when confronted with discordant situations, they might act avoidant to reduce possible threats to their identity. Finally, a diffuse-avoidant identity style is hypothesized to relate positively to less adaptive conflict resolution behaviors (e.g., withdrawal or conflict engagement) as diffuse-avoidant adolescents tend to postpone important decisions and use emotion-focused strategies to deal with problems.

Adolescents and mothers do not handle conflicts in a social vacuum. Their behaviors are interdependent (Van Doorn et al. 2008), meaning that adolescents' conflict resolution behaviors are influenced by the conflict behaviors of their mothers, and vice versa. For this reason, we decided to control for the conflict resolution styles of the mothers in our analyses in an attempt to capture the unique contribution of identity styles to adolescent conflict 
resolution styles. Further, although the identity style literature revealed no consistent empirical findings concerning gender differences (Berzonsky, in press), we explored possible interactions between adolescents' gender and identity styles to investigate whether gender would qualify or moderate the associations between identity styles and conflict behaviors. Similarly, because older adolescents generally have more mature ways of tackling both conflicts and identity-related issues, we explored whether age could function as a moderator in this relationship.

\section{Method}

\section{Participants and Procedure}

Participants were recruited from five secondary schools in Flanders, the Dutch-speaking part of Belgium. Our participants attended schools who mainly attract Caucasian students. The sample consisted of 860 adolescents and 819 mothers. Following matching, the final sample consisted of 796 adolescents (534 girls and 260 boys) and their mothers. The adolescents' age ranged from 14 to 20 years $(M=15.50, \mathrm{SD}=1.16)$. A total of 303 adolescents were in 9th grade (38.4\%), 275 adolescents in 10th grade (34.8\%), 120 adolescents in 11 th grade $(15.2 \%)$, and 92 adolescents in 12th grade $(11.6 \%)$. Six participants failed to report data regarding their grade level. Concerning family situation, $82.5 \%$ of the adolescents lived in intact families, the other $16.5 \%$ had divorced parents. The age of the mothers ranged from 34 to 61 years $(M=45.06, \mathrm{SD}=3.65)$. With respect to educational level of the mothers, $32.9 \%$ finished secondary school, $46.3 \%$ had a bachelor degree, and $11.1 \%$ had a university degree. To examine whether adolescents matched with a mother differed from non-matched adolescents, we conducted a multivariate analysis of variance (MANOVA). Significant mean differences emerged for conflict frequency, the information-oriented identity style, and the diffuseavoidant identity style (Wilks' $\lambda=.97 ; F(10,830)=2.73$, $p<.01)$. Non-matched adolescents reported a somewhat higher rate of weekly conflicts, were less information-oriented, and more diffuse-avoidant.

All adolescents received two envelopes (one for themselves and one for their mother) with an informed consent document, an information letter, and the questionnaire. According to the recommendations of the university's Institutional Review Board, informed consent was obtained from all participants. All participants were asked to fill out their questionnaires at home and bring them back to school within 2 weeks in the closed envelope. They were also requested to give an envelope to their mother. Teachers collected all the completed questionnaires in closed envelopes. Scale scores were computed when $80 \%$ of the items were completed. List wise deletion was applied, resulting in 771 participants (out of 796) included in all primary analyses.

\section{Measures}

\section{Identity Styles}

To assess identity styles, adolescents completed the Dutch version of the Identity Style Inventory-Version 4 (ISI-4; Smits et al. 2009). Items were scored on a 5-point Likert scale, ranging from 1 (strongly disagree) to 5 (strongly agree). The information-oriented scale (e.g., "When facing a life decision, I try to analyze the situation in order to understand it") consisted of 7 items, the normative scale (e.g. "I strive to achieve the goals my family and friends hold for me") of 8 items, and the diffuse-avoidant scale (e.g., "Many times, by not concerning myself with personal problems, they work themselves out") of 9 items. The ISI-4 is a revised version of the Identity Style Inventory-3 (ISI-3; Berzonsky 1990) and intends to assess the same three identity styles as the ISI-3. In order to remedy some of the psychometric shortcomings of the ISI-3, some items were reformulated and a number of new items were formulated. Smits et al. (2009) have demonstrated that the revised instrument had satisfactory test-retest reliability, stability, and construct validity. Test-retest correlations across a period of 4 months were $r=.63, .62$, and .66 for the information-oriented, the normative, and the diffuseavoidant style, respectively.

Because only a few published studies have used this revised measure, we performed Confirmatory Factor Analysis (CFA) using Lisrel $8.54^{\circledR}$ (Jöreskog and Sörbom 1993) to validate the factor structure of the ISI-4 in the present dataset. We used standard fit indices to evaluate model fit (Kline 2006). The Satorra-Bentler (1994) Scaled (SBS) $\chi^{2}$ should be as small as possible; the Root Mean Square Error of Approximation (RMSEA) should be less than .08 to indicate acceptable fit, and the Comparative Fit Index (CFI) should exceed .90 and preferably .95. Based on the modification indices, the measurement errors of two items (both items were from the diffuse-avoidant subscale and tapped into future-oriented decision-making) were allowed to correlate. CFA indicated that this three-factor model fitted the data adequately $(d f=248$, SBS$\chi^{2}=672.859$, RMSEA $=.05, \mathrm{CFI}=.90$ ). The standardized pattern coefficients for the items on their respective factors ranged between .27 and .68. Item 8 ("When others say something that challenges my personal values or beliefs, I automatically disregard what they have to say") of the normative subscale had a nonsignificant pattern coefficient and, consequently, was deleted. After deleting this item, the Cronbach's alpha of this scale increased from 
.62 to .65 . Cronbach's alphas of the information-oriented and diffuse-avoidant scales were .72 and .71 , respectively.

\section{Adolescents' Conflict Resolution Styles}

To measure how adolescents handle conflicts with their mothers, both adolescents and mothers completed a Dutch adaptation (Branje et al. 2009) of the Conflict Resolution Style Inventory (CRSI; Kurdek 1994). Kurdek's questionnaire was originally designed to measure conflict resolution in couples, but was adapted for the parenting context (Branje et al. 2009). The validity of this adapted measure regarding parent-adolescent relationships has been demonstrated in various studies (Van Doorn et al. 2007, 2008, in press). This questionnaire measures four conflict resolution styles: positive problem solving, conflict engagement, withdrawal, and compliance. On a 5-point Likert scale, ranging from 1 (never) to 5 (always), both mothers and adolescents rated how often the adolescents used particular conflict resolution strategies in relation to the mothers when they had an argument or quarrel. All four subscales consisted of 5 items and sample items included: "Trying to find solutions that are acceptable for both of us" (positive problem solving), "Letting myself go, and saying things I don't really mean" (conflict engagement), "Not listening to her anymore" (withdrawal), and "Not defending my opinion" (compliance).

CFA indicated that the four-factor model fitted the data adequately and this proved to be the case for both raters $\left(d f=164\right.$, SBS $-\chi^{2}=675.60$, RMSEA $=.06$, CFI $=.94$ for adolescent report; and $d f=164$, SBS- $\chi^{2}=430.47$, RMSEA $=.05$, CFI $=.97$ for mother report). The standardized pattern coefficients for the items on their respective factors ranged between .46 and .89 for adolescent report and between .38 and .91 for mother report. All four subscales had adequate internal consistencies for both raters: Positive problem solving $(\alpha=.88$ for adolescent report and .88 for mother report), conflict engagement $(\alpha=.79$ for adolescent report and .83 for mother report), withdrawal $(\alpha=.76$ for adolescent report and .80 for mother report), and compliance $(\alpha=.73$ for adolescent report and .66 for mother report).

We decided to use aggregated scores of adolescent and mother reports, consisting of the mean of both informants, in the remainder of the manuscript (interrater correlations were .39 for positive problem solving, .46 for conflict engagement, .29 for withdrawal, and .13 for compliance; all $p$ 's $<.001)$. Previous research on parent-adolescent relationships demonstrated that combining scores of multiple informants significantly reduces rater bias and Type I error rate (Holmbeck et al. 2002; Schwarz et al. 1985). Cronbach's alphas for the aggregated conflict resolution styles were .90 for positive problem solving, .84 for conflict engagement, .82 for withdrawal, and .74 for compliance. As suggested in the literature (Holmbeck et al. 2002), the alpha coefficients of the aggregated scales exceeded those of the individual scales.

\section{Mothers' Conflict Resolution Styles}

To measure how mothers handle conflicts with their adolescent children, the mothers completed the same adaptation (Branje et al. 2009) of the Conflict Resolution Style Inventory (CRSI; Kurdek 1994). In other words, mothers were asked to what extent they used the four conflict resolution styles outlined above when they had a conflict with their adolescents. Again, CFA indicated that the four-factor model fitted the data adequately $\left(d f=164\right.$, SBS- $\chi^{2}=$ 480.22, RMSEA $=.05, \quad$ CFI $=.97$ ). The standardized pattern coefficients for the items on their respective factors ranged between .51 and .85. All four subscales had adequate Cronbach's alphas: Positive problem solving $(\alpha=.86)$, conflict engagement $(\alpha=.80)$, withdrawal $(\alpha=.78)$, and compliance $(\alpha=.73)$.

\section{Frequency of Conflicts}

The frequency of conflicts between adolescents and mothers was measured with the Dutch translation (Branje et al. 2009) of the Interpersonal Conflict Questionnaire (ICQ; Laursen 1993). This questionnaire consists of 35 items covering potential conflict topics that were rated on a 5 -point Likert scale ranging from 1 (never) to 5 (often). Adolescents and mothers rated for each item how often they had conflicts, disagreements, or quarrels with each other about a specific topic during the last week. All conflict topics refer to the adolescent's behavior and not the mother's behavior. Items included issues like: "behavior in class or school", "what time you have to be in or out of bed", "cleaning, tidiness", and "where you go and what you do". Scores were averaged across the 35 items, providing us with an average weekly conflict score. Cronbach's alphas were .93 for the adolescent report and .95 for the mother report. We used aggregated scores of adolescent and mothers report in the remainder of the manuscript (interrater correlation was .46, $p<.001$ ). Cronbach's alpha for aggregated conflict frequency was .94 .

\section{Results}

Preliminary and Correlational Analyses

To examine whether the demographic variables of adolescents' gender, family situation, and maternal educational level had to be used as control variables in the 
primary analyses, we performed three one-way MANOVAs with the above mentioned demographic variables as fixed factors and identity styles, conflict frequency, and conflict resolution styles, respectively, as dependent variables. This yielded significant multivariate effects (Wilks' $\lambda=.97 ; F(8,697)=2.42, p<.05)$ for gender. Boys scored lower than girls on the information-oriented style and withdrawal. No significant multivariate effects were found for family situation and maternal educational level (Wilks' $\lambda=.99 ; F(8,697)=.62$, $n s$; and Wilks' $\lambda=.95 ; \quad F \quad(24,2022)=1.45, \quad n s, \quad$ respectively $)$. To examine whether adolescents' age had to be used as a control variable in the primary analyses, we computed correlations between age and the study variables. This yielded significant results for all variables except for the normative style and compliance. Older adolescents were more information-oriented and less diffuse avoidant ( $r$ 's $=$ .14 , and $-.15, p$ 's $<.001$, respectively), they also reported fewer conflicts and used more problem solving $(r$ 's $=$ -.15 , and $.16, p$ 's $<.001$, respectively), and fewer conflict engagement and withdrawal $(r=-.10, p<.01$, and $r=$ $-.08, p<.05$, respectively). As a result of these analyses, we decided to use adolescents' gender and age as control variables in the primary analyses. Descriptives (i.e., means and standard deviations) and correlations among the study variables are presented in Table 1.

Correlations between identity styles and conflict frequency were as follows. The information-oriented style related negatively to conflict frequency. The diffuseavoidant style related positively to conflict frequency. The normative style showed no significant relationship with conflict frequency. Regarding the link between conflict resolution styles and conflict frequency, we can conclude that, in general, more negative ways of dealing with conflicts (i.e., conflict engagement, withdrawal, and compliance) were associated with more weekly conflicts. Positive problem solving, by contrast, was associated with less weekly conflicts. This was the case for both mothers' and adolescents' ways of handling conflicts.

Correlations between the three identity styles and the four conflict resolution styles were to a large extent in line with our expectations. First, an information-oriented identity style was positively related to positive problem solving and negatively to conflict engagement and withdrawal. Second, normative individuals had a tendency towards compliance. Finally, the diffuse-avoidant style was negatively associated with positive problem solving and positively with conflict engagement, withdrawal, and compliance.

Table 1 Means, standard deviations, and correlations among the study variables

\begin{tabular}{|c|c|c|c|c|c|c|c|c|c|c|c|c|c|}
\hline Variable & $M$ & $\mathrm{SD}$ & 1 & 2 & 3 & 4 & 5 & 6 & 7 & 8 & 9 & 10 & 11 \\
\hline $\begin{array}{l}\text { 1. Positive problem } \\
\text { solving mother }\end{array}$ & 3.84 & .66 & & & & & & & & & & & \\
\hline $\begin{array}{l}\text { 2. Conflict } \\
\text { engagement } \\
\text { mother }\end{array}$ & 1.74 & .59 & $-.23 * * *$ & & & & & & & & & & \\
\hline $\begin{array}{l}\text { 3. Withdrawal } \\
\text { mother }\end{array}$ & 1.76 & .61 & $-.30 * * *$ & $.44 * * *$ & & & & & & & & & \\
\hline $\begin{array}{l}\text { 4. Compliance } \\
\text { mother }\end{array}$ & 2.04 & .61 & $-.15^{* * *}$ & $.28 * * *$ & $.39 * * *$ & & & & & & & & \\
\hline $\begin{array}{l}\text { 5. Information- } \\
\text { oriented style }\end{array}$ & 3.88 & .52 & $.13 * * *$ & $-.08 *$ & -.05 & .03 & & & & & & & \\
\hline 6. Normative style & 2.76 & .47 & .01 & -.01 & -.03 & -.02 & $.19 * * *$ & & & & & & \\
\hline $\begin{array}{l}\text { 7. Diffuse-avoidant } \\
\text { style }\end{array}$ & 2.68 & .59 & $-.13 * * *$ & .03 & $.08 *$ & .03 & $-.26^{* * *}$ & $.17 * * *$ & & & & & \\
\hline $\begin{array}{l}\text { 8. Conflict } \\
\text { frequency }\end{array}$ & 1.87 & .48 & $-.22 * * *$ & $.43 * * *$ & $.36 * * *$ & $.25 * * *$ & $-.22 * * *$ & -.03 & $.18 * * *$ & & & & \\
\hline $\begin{array}{l}\text { 9. Positive problem } \\
\text { solving adolescent }\end{array}$ & 3.16 & .71 & $.60 * * *$ & $-.23 * * *$ & $-.25 * * *$ & $-.08 *$ & $.33 * * *$ & .05 & $-.25 * * *$ & $-.30 * * *$ & & & \\
\hline $\begin{array}{l}\text { 10. Conflict } \\
\text { engagement } \\
\text { adolescent }\end{array}$ & 1.99 & .65 & $-.22 * * *$ & $.49 * * *$ & $.45 * * *$ & $.21 * * *$ & $-.16^{* * *}$ & -.03 & $.13 * * *$ & $.50 * * *$ & $-.34 * * *$ & & \\
\hline $\begin{array}{l}\text { 11. Withdrawal } \\
\text { adolescent }\end{array}$ & 2.27 & .61 & $-.29 * * *$ & $.30 * * *$ & $.46^{* * *}$ & $.22 * * *$ & $-.16^{* * *}$ & .01 & $.21 * * *$ & $.44 * * *$ & $-.45 * * *$ & $.45 * * *$ & \\
\hline $\begin{array}{l}\text { 12. Compliance } \\
\text { adolescent }\end{array}$ & 2.01 & .48 & -.06 & $.11 * *$ & $.09 *$ & $.30 * * *$ & .04 & $.10 * *$ & $.08 *$ & $.07 *$ & .03 & $-.10^{* *}$ & $.17 * * *$ \\
\hline
\end{tabular}

$* p<.05 ; * * p<.01 ; * * * p<.001$ 
Primary Analyses: Regression Analyses

We performed multiple hierarchical regression analyses with two-way interaction terms, separately for the five dependent variables (i.e., conflict frequency and the four conflict resolution styles). In Step 1, the background variables (i.e., gender and age) were entered as control variables. The second set of control variables, that is, mothers' conflict resolution styles, was entered in Step 2. The main effects of identity styles were entered in Step 3. In Step 4, the six interaction terms between identity styles and age and gender were entered simultaneously as a chunk (Jaccard and Turrisi 2003). Table 2 presents the standardized betas and the $R^{2}$-values for the subsequent steps in the regression analyses.

In Step 1, the variables added significantly to the prediction of nearly all outcome variables. This was due to the effect of age on conflict frequency, conflict engagement, problem solving, and withdrawal. More specifically, older adolescents, compared to younger adolescents, reported fewer weekly conflicts, and were more inclined to use positive problem solving, and less inclined to use conflict engagement and withdrawal when having conflicts with their mother. The maternal conflict resolution styles (Step 2) also added significantly to the prediction of all outcome variables. More specifically, mother's negative ways of handling conflict related positively to conflict frequency. Positive problem solving related negatively to conflict frequency. Maternal positive problem solving was strongly positively associated with adolescents' positive problem solving and slightly negatively to adolescents' conflict engagement. Maternal conflict engagement was positively related to adolescents' conflict engagement and withdrawal, and negatively to adolescents' problem solving. Maternal withdrawal was positively related to both adolescents' withdrawal and conflict engagement. Finally, maternal compliance was positively related to compliance of the adolescent. The most remarkable finding was that the maternal conflict style had the strongest relationship with the corresponding adolescent conflict style.

The main effects of identity styles (Step 3) explained an additional significant proportion of the variance in all outcome variables. First, the information-oriented identity style was negatively associated with conflict frequency, conflict engagement, and withdrawal, and positively with positive problem solving. Second, the diffuse-avoidant identity style showed the exact reverse pattern of associations. Third, the normative identity style was positively related to compliance but unrelated to each of the other outcomes.

Table 2 Hierarchical regression of conflict frequency and adolescent conflict resolution styles on identity styles

\begin{tabular}{|c|c|c|c|c|c|c|c|c|c|c|}
\hline \multirow[t]{2}{*}{ Predictor } & \multicolumn{2}{|c|}{ Conflict frequency } & \multicolumn{2}{|c|}{ Problem solving } & \multicolumn{2}{|c|}{ Conflict engagement } & \multicolumn{2}{|c|}{ Withdrawal } & \multicolumn{2}{|c|}{ Compliance } \\
\hline & $\beta$ & $\Delta R^{2}$ & $\beta$ & $\Delta R^{2}$ & $\beta$ & $\Delta R^{2}$ & $\beta$ & $\Delta R^{2}$ & $\beta$ & $\Delta R^{2}$ \\
\hline Step 1: Demographics & & $.02 * * *$ & & $.03 * * *$ & & $.01 *$ & & $.01 *$ & & .00 \\
\hline Age & $-.14 * * *$ & & $.17 * * *$ & & $-.09 * *$ & & $-.08 *$ & & .03 & \\
\hline Gender & -.03 & & .01 & & .04 & & .06 & & -.04 & \\
\hline Step 2: Mothers' style & & $.21 * * *$ & & $.36 * * *$ & & $.30 * * *$ & & $.23 * * *$ & & $.10 * * *$ \\
\hline Problem solving mother & $-.09 * *$ & & $.57 * * *$ & & -.06 & & $-.14 * * *$ & & -.03 & \\
\hline Engagement mother & $.30 * * *$ & & $-.07 *$ & & $.35 * * *$ & & $.11^{* *}$ & & .04 & \\
\hline Withdrawal mother & $.16^{* * *}$ & & -.05 & & $.28 * * *$ & & $.36^{* * *}$ & & -.05 & \\
\hline Compliance mother & $.09 * *$ & & .05 & & -.01 & & .02 & & $.32 * * *$ & \\
\hline Step 3: Main effects & & $.04 * *$ & & $.06 * * *$ & & $.02 * * *$ & & $.03 * * *$ & & $.02 * *$ \\
\hline Information-oriented & $-.14 * * *$ & & $.21 * * *$ & & $-.10^{* *}$ & & $-.10^{* *}$ & & .04 & \\
\hline Normative & -.02 & & .03 & & -.00 & & .02 & & $.09 *$ & \\
\hline Diffuse-avoidant & $.11 * * *$ & & $-.10 * * *$ & & $.07 *$ & & $.14 * * *$ & & .07 & \\
\hline Step 4: Interaction effects & & .00 & & .00 & & .00 & & .01 & & $.03 * * *$ \\
\hline Age $\times$ Info & .01 & & -.01 & & .04 & & -.05 & & $-.15 * * *$ & \\
\hline Age $\times$ Norm & .03 & & -.04 & & .00 & & .04 & & .02 & \\
\hline Age $\times$ Dif & -.01 & & -.05 & & -.02 & & -.02 & & $-.10^{* *}$ & \\
\hline Gender $\times$ Info & .06 & & -.08 & & .05 & & .01 & & -.05 & \\
\hline Gender $\times$ Norm & .00 & & .08 & & -.07 & & .11 & & $.20 * *$ & \\
\hline Gender $\times$ Dif & -.02 & & -.09 & & .02 & & .08 & & -.04 & \\
\hline
\end{tabular}

Info information-oriented identity style, norm normative identity style; dif diffuse-avoidant identity style

$* p<.05 ; * * p<.01 ; * * * p<.001$ 
Finally, the interaction effects (Step 4) added significantly to the prediction of compliance, but not to any of the other outcomes. For age, significant interactions were found with the information-oriented and the diffuseavoidant style. Subsequent simple slopes analyses indicated that the simple slopes were $.19(t=2.56, p<.05)$ and $.16(t=2.38, p<.05)$, respectively, at low levels of age (i.e., $1 \mathrm{SD}$ below the mean). At high levels of age (i.e., 1SD above the mean), the simple slopes were -.09 ( $t=$ $-1.27, p=0.21)$ and $-.01(t=-.11, p=.91)$, respectively. Hence, an information-oriented identity style and a diffuse-avoidant style were positively related to compliance but only for younger adolescents. For gender, a significant positive interaction was found with the normative style. The simple slope was .17 for girls $(t=3.69, p<$ $.001)$, and -.08 for boys $(t=-1.30, p=0.19)$, showing that a normative style was positively associated with the use of compliance, but only for girls.

\section{Discussion}

Establishing a firm sense of identity (Marcia 1966) and learning to resolve conflicts with family members in constructive ways (Collins and Laursen 1992) are important developmental tasks in adolescence. Few studies, however, have examined the link between identity formation and conflict resolution. The goal of the current multi-informant study was to examine associations between adolescent identity styles and conflict behaviors (i.e., frequency and resolution styles), specifically as they apply in the mother-adolescent relationship. Several important findings were uncovered in the present study.

First, concerning the link between identity styles and conflict frequency, our hypotheses were partially confirmed. Adolescents who primarily use an informationoriented style of processing identity-relevant issues tended to have fewer conflicts with their mothers. Adolescents with a diffuse-avoidant identity style experienced more conflicts with their mothers. Contrary to expectations, no association was found between the normative identity style and conflict frequency. Hence, future research could focus on possible moderating variables in this association. Previous research indicated that the normative identity style could be rooted in both authoritative and authoritarian parenting climates (Berzonsky 2004). Relatedly, different motives could instigate adolescents to use a normative identity style. Whereas some adolescents feel pressured by their parents to adhere to parental norms and values, others may autonomously and willingly follow parental advice and norms (Smits et al. 2010). Hence, conflicts may be more likely to arise in the former kind of families, that is, in families in which adolescents feel pressured to adopt a normative stance on self-defining issues.

Second, the present study examined the relationships between adolescents' identity styles and conflict resolution styles in relationship to their mothers. In general, after controlling for conflict resolution styles of the mother, each identity style was found to relate to a specific conflict resolution style in adolescents. The information-oriented identity style was positively related to positive problem solving, which is in line with our hypothesis that information-oriented individuals are open-minded and endorse several perspectives when facing a conflict. Previous research indeed demonstrated that the information-oriented style was positively associated with empathy and perspective taking (Smits et al., in press), which are essential ingredients for engaging in positive problem solving (De Wied et al. 2007). Additionally, the informationoriented style was negatively associated with unconstructive ways of dealing with conflicts, such as withdrawal and engagement. In sum, the information-oriented style was related to the most optimal pattern of conflict resolution styles.

As expected, the normative identity style was positively associated with the use of compliance, but moderation analyses indicated that this was mainly the case for girls. Adolescent girls who tend to rely primarily on authority figures to process important identity-relevant information were inclined to give into their mother when confronted with conflicts. Contrary to our expectations, we found no association between the normative identity style and the use of withdrawal. A possible explanation might be that a normative style is typically characterized by a passive, submissive, and obedient orientation towards parents and other authority figures (Soenens et al. 2005). Consequently, future research might do well to differentiate between conflicts inside and outside the parent-adolescent relationship. Because normative adolescents tend to adopt the values and norms their parents hold for them, conflicts over those issues might be solved primarily in an atmosphere of compliance and obedience. However, it might be interesting to investigate whether normative individuals are more inclined to use withdrawal when they have a quarrel with non-authority figures like peers or siblings. Alternatively, compliance could also be considered as a subtle avoidant conflict strategy (Smetana et al. 1991): by giving into the other party, one refuses to express one's opinion.

Finally, and consistent with our hypotheses, the diffuseavoidant identity style related positively to the maladaptive conflict resolution style of withdrawal. Adolescents who adopt a diffuse-avoidant way of dealing with identity issues were inclined to use withdrawal when facing a conflict with their mother. A negative association with positive problem solving was also found. This is in line with recent work by Smits et al. (in press) in which a negative association was 
found between the diffuse-avoidant style and empathy. Lacking the capacity to adopt the perspective of the other potentially hinders diffuse-avoidant adolescents to solve a conflict by means of negotiation and compromise. We also found the anticipated positive association between the diffuse-avoidant style and conflict engagement. In addition to their strategy of withdrawal, diffuse adolescents seem to have a tendency to engage aggressively in a conflict.

Two plausible explanations can be advanced for the associations between the diffuse-avoidant style and these two diverging maladaptive conflict resolution styles. First, multiple conflict resolution styles can be used when dealing with conflicts. Branje et al. (2009) found five clusters of conflict resolution styles. The Negative cluster was characterized by very high levels of destructive conflict resolution styles, such as conflict engagement and withdrawal. Second, individuals who use a diffuse-avoidant style might constitute a heterogeneous group (Archer and Waterman 1990; Berzonsky 1985; Marcia 1989). Luyckx et al. (2005, 2008) empirically distinguished between two different types of diffusion, that is, diffused diffusion and carefree diffusion. Adolescents in the former group were described as suffering from their indecisiveness and lack of commitments. Such individuals were found to display a less adjusted profile (in terms of academic performance and internalizing problems) as compared to their carefree counterparts. Future research could investigate whether these two groups handle conflicts in a different manner.

\section{Limitations and Suggestions for Future Research}

Despite the use of multiple informants and the large sample size, some limitations of our study need to be mentioned. First, the sample consisted primarily of Caucasian Dutchspeaking high school students and their mothers. Therefore, we cannot state with certainty that our findings can be generalized to fathers and families from different ethnic backgrounds. Especially the finding that the normative style was associated with compliance only for girls warrants further investigation. Future research could examine whether such an association also holds for the fatherdaughter dyad or father-son dyad.

Second, regarding conflict resolution behaviors, the present study used questionnaires to assess conflict resolution styles in general, instead of relying on real conflict situations. Smetana et al. (1991) demonstrated that hypothetical conflict scenarios evoked more adaptive conflict resolution behaviors than those elicited by actual conflicts. Similarly, conflict frequency was measured by presenting participants a non-exhaustive list of potential conflict topics. Again, interviews and natural observations (Burk et al. 2009) could offer a more realistic picture about the content and frequency of parent-adolescent conflicts.
Third, data were cross-sectional in nature, which prevents us from drawing conclusions about the direction of effects. In all regression analyses, identity styles were modeled as predictors of conflict resolution behaviors. This approach was adopted, in part, because identity styles are assumed to be more stable and more deeply rooted in one's personality (Berzonsky 1990) than conflict resolution behaviors, which have been demonstrated to be more situationally dependent (Smetana et al. 1991). However, as stated in the introduction, adolescents' identity styles and conflict resolution styles most likely influence one another in a reciprocal fashion. Hence, longitudinal research studying the dynamics between identity development and conflict resolution behaviors is needed.

Finally, future research attempts should assess other variables that might be important in the association between identity and conflict behaviors. As noted earlier, parenting dimensions, such as support, regulation, and psychological control (Barber et al. 2005), can serve as possible moderators. Future research might also shed light on the finding in our interaction analyses that, for young adolescents, both the information-oriented and diffuseavoidant style seemed to relate positively to compliance.

Despite these limitations, the present study added significantly to the literature on adolescent development and may have important clinical implications. The way adolescents process identity-relevant information in making important life choices was accompanied by a certain amount of conflict and, more importantly, by a certain style of resolving these conflicts. In other words, identity processing styles are not only significant markers for adolescents' intrapersonal functioning but they also relate to the way adolescents deal with difficulties in their families. Young people experiencing difficulties in establishing a clear identity are especially in need of extra care. These diffuse adolescents seem to lack the effective tools to handle conflicts with their mothers. Non-constructive ways of handling conflicts are associated with internalizing and externalizing problems (Branje et al. 2009; Tucker et al. 2003). Furthermore, this lack of problem solving skills can potentially generalize to relationships outside the family context, such as interactions with peers and teachers. Hence, provided that the present findings are replicated in independent samples, prevention efforts should try to identify vulnerable adolescents and teach them effective ways of dealing with identityrelevant issues and interpersonal conflicts.

\section{References}

Adams, R., \& Laursen, B. (2001). The organization and dynamics of conflict with parents and friends. Journal of Marriage and Family, 63, 97-110. 
Adams, R. E., \& Laursen, B. (2007). The correlates of conflict: Disagreement is not necessarily detrimental. Journal of Family Psychology, 21, 445-458.

Adams, G. R., \& Marshall, S. K. (1996). A developmental social psychology of identity: Understanding the person-in-context. Journal of Adolescence, 19, 429-442.

Adams, G. R., Munro, B., Doherty-Poirer, M., Munro, G., Petersen, A. R., \& Edwards, J. (2001). Diffuse-avoidance, normative, and information-oriented identity styles: Using identity theory to predict maladjustment. Identity: An International Journal of Theory and Research, 1, 307-320.

Archer, S. L., \& Waterman, A. S. (1990). Varieties of identity diffusions and foreclosures: An exploration of subcategories of the identity statuses. Journal of Adolescent Research, 5, 96-111.

Barber, B. K., Stolz, H. E., \& Olsen, J. A. (2005). Parental support, psychological control, and behavioral control: Assessing relevance across time, method, and culture. Monographs of the Society for research in Child Development, 70(4, Serial No. 282).

Berzonsky, M. D. (1985). Diffusion within Marcia identity-status paradigm: Does it foreshadow academic problems? Journal of Youth and Adolescence, 14, 527-538.

Berzonsky, M. D. (1989). Identity style: Conceptualization and measurement. Journal of Adolescent Research, 4, 268-282.

Berzonsky, M. D. (1990). Self-construction over the life-span: A process perspective on identity formation. In G. J. Neimeyer \& R. A. Neimeyer (Eds.), Advances in personal construct psychology (Vol. 1, pp. 155-186). Greenwich, CT: JAI Press.

Berzonsky, M. D. (1992). Identity style and coping strategies. Journal of Personality, 60, 771-788.

Berzonsky, M. D. (2004). Identity style, parental authority, and identity commitment. Journal of Youth and Adolescence, 33, 213-220.

Berzonsky, M. D. (in press). A social-cognitive perspective on identity construction. In S. J. Schwartz, K. Luyckx, \& V. L. Vignoles (Eds.), Handbook of identity theory and research. New York: Springer.

Berzonsky, M. D., Branje, S. J. T., \& Meeus, W. (2007). Identity processing style, psychosocial resources, and adolescents' perceptions of parent-adolescent relations. Journal of Early Adolescence, 27, 324-345.

Berzonsky, M. D., \& Sullivan, C. (1992). Social-cognitive aspects of identity style: Need for cognition, experiential openness, and introspection. Journal of Adolescent Research, 7, 140-155.

Bosma, H. A., \& Kunnen, E. S. (2001). Determinants and mechanisms in ego identity development: A review and synthesis. Developmental Review, 21, 39-66.

Branje, S. J. T., Van Doorn, M. D., Van der Valk, I., \& Meeus, W. H. J. (2009). Parent-adolescent conflicts, conflict resolution types, and adolescent adjustment. Journal of Applied Developmental Psychology, 30, 195-204.

Bronfenbrenner, U. (1989). Ecological system theory. In R. Vasta (Ed.), Annals of child development (Vol. 6, pp. 187-249). Greenwich, CT: JAI Press.

Burk, W. J., Denissen, J., Van Doorn, M., Branje, S. J. T., \& Laursen, B. (2009). The vicissitudes of conflict measurement: Stability and reliability in the frequency of disagreements. European Psychologist, 14, 153-159.

Collins, W. A., \& Laursen, B. (1992). Conflicts and relationships during adolescence. In C. U. Shantz \& W. W. Hartup (Eds.), Conflict in child and adolescent development (pp. 216-241). New York: Cambridge University Press.

Collins, W. A., Laursen, B., Mortensen, N., Luebker, C., \& Ferreira, M. (1997). Conflict processes and transitions in parent and peer relationships: Implications for autonomy and regulation. Journal of Adolescent Research, 12, 178-198.
De Goede, I. H. A., Branje, S. J. T., \& Meeus, W. H. J. (2009). Developmental changes in adolescents' perceptions of relationships with their parents. Journal of Youth and Adolescence, 38, 75-88.

De Wied, M., Branje, S. J. T., \& Meeus, W. H. J. (2007). Empathy and conflict resolution in friendship relationships among adolescents. Aggressive Behavior, 33, 48-55.

Deković, M., Noom, M. J., \& Meeus, W. (1997). Expectations regarding development during adolescence: Parental and adolescent perceptions. Journal of Youth and Adolescence, 26, 253-272.

Erikson, E. H. (1968). Identity: Youth and crisis. New York: Norton.

Goossens, L. (2006). The many faces of adolescent autonomy: Parentadolescent conflict, behavioral decision-making, and emotional distancing. In S. Jackson \& L. Goossens (Eds.), Handbook of adolescent development (pp. 135-153). Hove, UK: Psychology Press.

Grotevant, H. D., \& Cooper, C. R. (1985). Patterns of interaction in family relationships and the development of identity exploration in adolescence. Child Development, 56, 415-428.

Holmbeck, G. N., Li, S. T., Schurman, J. V., Friedman, D., \& Coakley, R. M. (2002). Collecting and managing multisource and multimethod data in studies of pediatric populations. Journal of Pediatric Psychology, 27, 5-18.

Jaccard, J., \& Turrisi, R. (2003). Interaction effects in multiple regression (2nd ed.). Thousand Oaks, CA: Sage.

Jöreskog, K. G., \& Sörbom, D. (1993). LISREL VIII users' reference guide. Mooresville, IN: Scientific Software.

Kline, R. B. (2006). Principles and practices of structural equation modeling (2nd ed.). New York: Guilford Press.

Kroger, J. (2003). Identity development during adolescence. In G. R. Adams \& M. D. Berzonsky (Eds.), Blackwell handbook of adolescence (pp. 205-226). Malden, MA: Blackwell.

Kunnen, S. (2006). Are conflicts the motor in identity change? Identity: An International Journal of Theory and Research, 6, 169-186.

Kurdek, L. A. (1994). Conflict resolution styles in gay, lesbian, heterosexual nonparent, and heterosexual parent couples. Journal of Marriage and the Family, 56, 705-722.

Laursen, B. (1993). The perceived impact of conflict on adolescent relationships. Merrill-Palmer Quarterly, 39, 535-550.

Laursen, B., \& Collins, W. A. (1994). Interpersonal conflict during adolescence. Psychological Bulletin, 115, 197-209.

Laursen, B., Coy, K. C., \& Collins, W. A. (1998). Reconsidering changes in parent-child conflict across adolescence: A metaanalysis. Child Development, 69, 817-832.

Laursen, B., Finkelstein, B. D., \& Townsend-Betts, N. (2001). A developmental meta-analysis of peer-conflict resolution. Developmental Review, 21, 423-449.

Lichtwarck-Aschoff, A., van Geert, P., Bosma, H., \& Kunnen, S. (2008). Time and identity: A framework for research and theory formation. Developmental Review, 28, 370-400.

Luyckx, K., Goossens, L., Beyers, W., \& Vansteenkiste, M. (2005). Identity statuses based upon four rather than two identity dimensions: Extending and refining Marcia's paradigm. Journal of Youth and Adolescence, 34, 605-618.

Luyckx, K., Lens, W., Smits, I., \& Goossens, L. (2010). Time perspective and identity formation: Short-term longitudinal dynamics in college students. International Journal of Behavioral Development, 34, 238-247.

Luyckx, K., Schwartz, S. J., Berzonsky, M. D., Soenens, B., Vansteenkiste, M., Smits, I., et al. (2008). Capturing ruminative exploration: Extending the four- dimensional model of identity formation in late adolescence. Journal of Research in Personality, 42, 58-82.

Marcia, J. E. (1966). Development and validation of ego-identity status. Journal of Personality and Social Psychology, 3, $551-558$. 
Marcia, J. E. (1989). Identity diffusion differentiated. In M. A. Luszcz \& T. Nettelbeck (Eds.), Psychological development: Perspectives across the life-span (pp. 123-137). Dordrecht, The Netherlands: Elsevier.

McGue, M., Elkins, I., Walden, B., \& Iacono, W. G. (2005). Perceptions of the parent-adolescent relationship: A longitudinal investigation. Developmental Psychology, 41, 971-984.

Montemayor, R., \& Hanson, E. (1985). A naturalistic view of conflict between adolescents and their parents and siblings. Journal of Early Adolescence, 5, 23-30.

Nurmi, J., Berzonsky, M. D., Tammi, K., \& Kinney, A. (1997). Identity processing orientation, cognitive and behavioral strategies, and well-being. International Journal of Behavioral Development, 27, 555-570.

Rubenstein, J. L., \& Feldman, S. S. (1993). Conflict-resolution behavior in adolescent boys: Antecedents and adaptational correlates. Journal of Research on Adolescence, 3, 41-66.

Satorra, A., \& Bentler, P. M. (1994). Corrections to test statistics and standard errors in covariance structure analysis. In A. Von Eye \& C. C. Clogg (Eds.), Latent variables analysis: Applications for developmental research (pp. 399-419). Thousand Oaks, CA: Sage.

Schwarz, J. C., Barton-Henry, M. L., \& Pruzinsky, T. (1985). Assessing child rearing behaviors: A comparison of ratings made by mother, father, child and sibling on the CRPBI. Child Development, 56, 462-479.

Shantz, C. U. (1987). Conflict between children. Child Development, $58,283-305$.

Smetana, J. G. (1989). Adolescents' and parents' reasoning about actual family conflict. Child Development, 60, 1052-1067.

Smetana, J. G., Daddis, C., \& Chuang, S. S. (2003). "Clean your room!" A longitudinal investigation of adolescent-parent conflict and conflict resolution in middle-class African American families. Journal of Adolescent Research, 18, 631-650.

Smetana, J. G., Yau, J., \& Hanson, S. (1991). Conflict resolution in families with adolescents. Journal of Research on Adolescence, 1, 189-206.

Smits, I., Doumen, S., Luyckx, K., Duriez, B., \& Goossens, L. (in press). Identity styles and interpersonal behavior in emerging adulthood: The intervening role of empathy. Social Development.

Smits, I., Soenens, B., Berzonsky, M. D., Luyckx, K., Goossens, L., Kunnen, S., et al. (2009). The identity style inventory-Version 4: A cross-national study in scale development and validation. In L. Goossens (Chair), Capturing identity styles: A cross-national and multi-method view on measurement. Symposium conducted at the 16th annual conference of the Society for Research on Identity Formation (SRIF), Pacific Grove, CA

Smits, I., Soenens, B., Luyckx, K., Duriez, B., Berzonsky, M. D., \& Goossens, L. (2008). Perceived parenting dimensions and identity styles: Exploring the socialization of adolescents' processing of identity-relevant information. Journal of Adolescence, 31, 151-164.

Smits, I., Soenens, B., Vansteenkiste, M., Luyckx, K., \& Goossens, L. (2010). Why do adolescents gather information or stick to parental norms? Examining autonomous and controlled motives behind adolescents' identity style. Journal of Youth and Adolescence, 39, 1343-1356.
Soenens, B., Duriez, B., \& Goossens, L. (2005). Social-psychological profiles of identity styles: Attitudinal and social-cognitive correlates in late adolescence. Journal of Adolescence, 28, 107-125.

Steinberg, L. (1990). Interdependency in the family: Autonomy, conflict, and harmony in the parent-adolescent relationship. In S. Feldman \& G. Elliot (Eds.), At the threshold: The developing adolescent (pp. 255-276). Cambridge, MA: Harvard University Press.

Tucker, C. J., McHale, S. M., \& Crouter, A. C. (2003). Conflict resolution: Links with adolescents' family relationships and individual well-being. Journal of Family Issues, 24(6), 715-736.

Van Doorn, M. D., Branje, S. J. T., \& Meeus, W. H. J. (2007). Longitudinal transmission of conflict resolution styles from marital relationships to parent-adolescent relationships. Journal of Family Psychology, 21, 426-434.

Van Doorn, M. D., Branje, S. J. T., \& Meeus, W. H. J. (2008). Conflict resolution in parent- adolescent relationships and adolescent delinquency. Journal of Early Adolescence, 28, 503-527.

Van Doorn, M. D., Branje, S. J. T., \& Meeus, W. H. J. (in press). Developmental changes in conflict resolution styles in parentadolescent relationships: A four-wave longitudinal study. Journal of Youth and Adolescence.

Youniss, J., \& Smollar, J. (1985). Adolescent relations with mothers, fathers and friends. Chicago: University of Chicago Press.

\section{Author Biographies}

Lies Christine Missotten is a $\mathrm{PhD}$ student at the Catholic University of Leuven, Belgium. She received her master's degree in 2005. Her major research interests include adolescent identity, conflict resolution in the parent-adolescent relationship, and parenting.

Koen Luyckx is a Postdoctoral Researcher at the Fund of Scientific Research (FWO)-Flanders (Belgium). He received his $\mathrm{PhD}$ in developmental psychology in 2006 from the Catholic University of Leuven, Belgium. His major research interests include identity, personality, parenting, and chronic illness.

Susan Branje is an Associate Professor at Utrecht University, The Netherlands. She received her $\mathrm{PhD}$ in 2003 from the Radboud University Nijmegen, The Netherlands. Her major research interests include adolescent development and the influence of parents and friends.

Janne Vanhalst is a $\mathrm{PhD}$ student at the Catholic University of Leuven, Belgium. She received her master's degree in 2008. Her major research interests include the development of loneliness during adolescence and the influence of parents and peers.

Luc Goossens is Full Professor in Developmental Psychology, Catholic University of Leuven, Belgium. He received his PhD in 1998 from the Catholic University of Leuven, Belgium. His major research interests include adolescent identity, autonomy, and loneliness. 